\title{
Comparative effectiveness of laparoscopic versus hysteroscopic approach in patients with previous cesarean scar defect: a retrospective cohort study
}

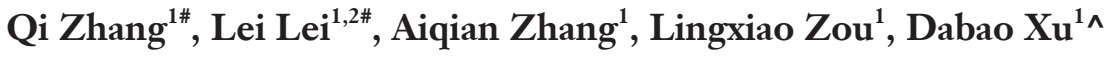 \\ ${ }^{1}$ Department of Obstetrics and Gynecology, Third Xiangya Hospital, Central South University, Changsha, China; ${ }^{2}$ Medical Center of Hysteroscopy, \\ Obstetrics and Gynecology Hospital of Fudan University, Shanghai, China \\ Contributions: (I) Conception and design: D Xu, Q Zhang, L Lei; (II) Administrative support: D Xu; (III) Provision of study materials or patients: Q \\ Zhang, L Lei; (IV) Collection and assembly of data: Q Zhang, L Lei; (V) Data analysis and interpretation: A Zhang, L Zou; (VI) Manuscript writing: \\ All authors; (VII) Final approval of manuscript: All authors. \\ \#These authors contributed equally to this work and should be considered as co-first authors. \\ Correspondence to: Dabao Xu. Department of Obstetrics and Gynecology, Third Xiangya Hospital, Central South University, 138 Tongzipo Road, \\ Changsha 410013, China. Email: dabaoxu@yahoo.com.
}

Background: The aim of this study was to evaluate the clinical effectiveness and obstetric outcomes of laparoscopic and hysteroscopic surgery in patients with previous cesarean scar defect (PCSD).

Methods: A retrospective cohort analysis was performed on women who underwent laparoscopic or hysteroscopic surgery for PCSD from 2016 to 2019 at the Third Xiangya Hospital of Central South University. Among these participants, 13 underwent laparoscopic surgery and 33 received hysteroscopic surgery.

Results: Significant differences were displayed in the operative times $(156.9 \pm 42.3$ vs. $40.7 \pm 38.9 \mathrm{~min}$, $\mathrm{P}<0.05)$, intra-operative blood loss $(80.0 \pm 61.0$ vs. $17.9 \pm 51.2 \mathrm{~mL}, \mathrm{P}<0.05)$, hospital stay $(7.1 \pm 1.6$ vs. $4.1 \pm 2.1$ days, $\mathrm{P}<0.05)$, postoperative hospital stay $(4.3 \pm 0.8$ vs. $1.5 \pm 1.1$ days, $\mathrm{P}<0.05)$, and hospitalization expenses $(22,240.3 \pm 249.9$ vs. 9,547.1 $\pm 4,747.2$ yuan, $\mathrm{P}<0.05)$ between the laparoscopic surgery and hysteroscopic group. No significant difference was observed in the incidence of clinical efficacy between the laparoscopic and hysteroscopic surgery group. A total of 2 of the 4 patients in the laparoscopic surgery group, and 9 of 11 patients in the hysteroscopic surgery group delivered successfully. All 2 participants in the laparoscopic surgery group and 2 participants in the hysteroscopic surgery group were diagnosed with placenta previa. No uterine rupture was reported in our study.

Conclusions: Both laparoscopic and hysteroscopic surgery are safe and effective treatments for PCSD patients, and hysteroscopic surgery is more efficient for PCSD patients.

Keywords: Previous cesarean scar defect (PCSD); laparoscopy; hysteroscopy; clinical effectiveness; surgical approach

Submitted Aug 01, 2021. Accepted for publication Sep 24, 2021.

doi: $10.21037 / \mathrm{atm}-21-4339$

View this article at: https://dx.doi.org/10.21037/atm-21-4339

$\wedge$ ORCID: 0000-0002-5455-5592. 


\section{Introduction}

The increasing rate of cesarean section delivery is a global public health challenge. Although various intervention strategies have been implemented to reduce the cesarean section (CS) rates in China, the overall rate has remained high (1-4). Consequently, cesarean-associated complications are on the rise. Previous cesarean scar defect (PCSD), a long-term complication of cesarean section, is the formation of a myometrial defect at the site of a previous cesarean incision on the anterior wall of the lower uterine segment, uterine isthmus, or in the upper segment of the cervical canal $(5,6)$. Several symptoms, including abnormal uterine bleeding, postmenstrual spotting or intermenstrual bleeding, menorrhagia, dysmenorrhea, chronic pelvic pain, and secondary infertility, are associated with PCSD (5-8).

The underlying pathogenesis and risk factors of PCSD are still unclear $(6,8)$. It has been alluded those factors such as the number of cesarean sections, location of the incision, uterine position, labor before cesarean section, surgical technique, and the wound recovery may play important roles in the development of PCSD $(6,8,9)$.

The evaluation of PCSD can be performed with a variety of methods, including transvaginal ultrasound (TVUS), saline infusion sonohysterography (SIS), magnetic resonance imaging (MRI), and hysteroscopy $(6,9)$. As an affordable and noninvasive method, TVUS is the most frequently used approach for the detection and screening of PCSD $(9,10)$. The imaging method of MRI is rather accurate and efficient for diagnosing PCSD (11), especially in displaying the specific structure in sagittal view. Meanwhile, hysteroscopy can provide the direct visualization for the detection and characterization of PCSD, and is also the potential treatment $(6,10)$. The surgical therapeutic options for PCSD patients include laparoscopic, hysteroscopic, and transvaginal surgery, and endometrial ablation (9). Since there is no guideline for PCSD management, various surgical approaches and techniques have been recommended in different studies. Our study aimed to evaluate the clinical effectiveness and obstetric outcomes of the commonly applied approaches of laparoscopic and hysteroscopic surgery for PCSD. We present the following article in accordance with the STROBE reporting checklist (available at https://dx.doi. org/10.21037/atm-21-4339).

\section{Methods}

\section{Patients}

Patients (N=81) with symptomatic PCSD who underwent laparoscopic or hysteroscopic surgery in the Gynecology Department of Third Xiangya Hospital of Central South University from 2016 to 2019 were retrospectively recruited to our study. All surgical procedures in this study were performed by Dr. Dabao Xu, and the steps of the surgery are summarized below. The diagnosis of PCSD was based on the medical history of patients, clinical examination, and imaging findings of TVUS and MRI. All participants underwent laparoscopic or hysteroscopic surgery within 1 week after menstruation. The exclusion criteria were as follows: (I) patients with concurrent pregnancy or lactation; (II) patients with acute general inflammation, especially in pelvic, or uncontrolled systemic disease; (III) patients with malignant tumors or precancerous lesions; (IV) patients with other identified causes of abnormal uterine bleeding or infertility; (V) patients who refused to accept corresponding follow-up. A total of 46 patients $(n=46)$ were identified according to above criteria. The flow chart for detailed patients' selection is presented in Figure 1.

\section{Ethical statement}

All procedures performed in this study involving human participants were in accordance with the Declaration of Helsinki (as revised in 2013). This study protocol was approved by the Ethics Committee of Third Xiangya Hospital of Central South University (No: 2020-S625). The diagnosis and treatment of participants were performed under standard procedures. All participants were fully informed of surgical procedures, the benefits, potential risks, and outcomes of the treatment before the surgery. All participants provided informed consent.

\section{Laparoscopic surgery}

The laparoscopic surgery was mainly performed among patients who had expressed desire for future pregnancy and residual myometrium (RM) less than $3 \mathrm{~mm}$, and the surgery procedures were as described in previous publication (12). Using an ultrasonic scalpel (Ethicon Inc. Somerville, NJ, USA) and bipolar coagulation forceps (Kangji Co., 


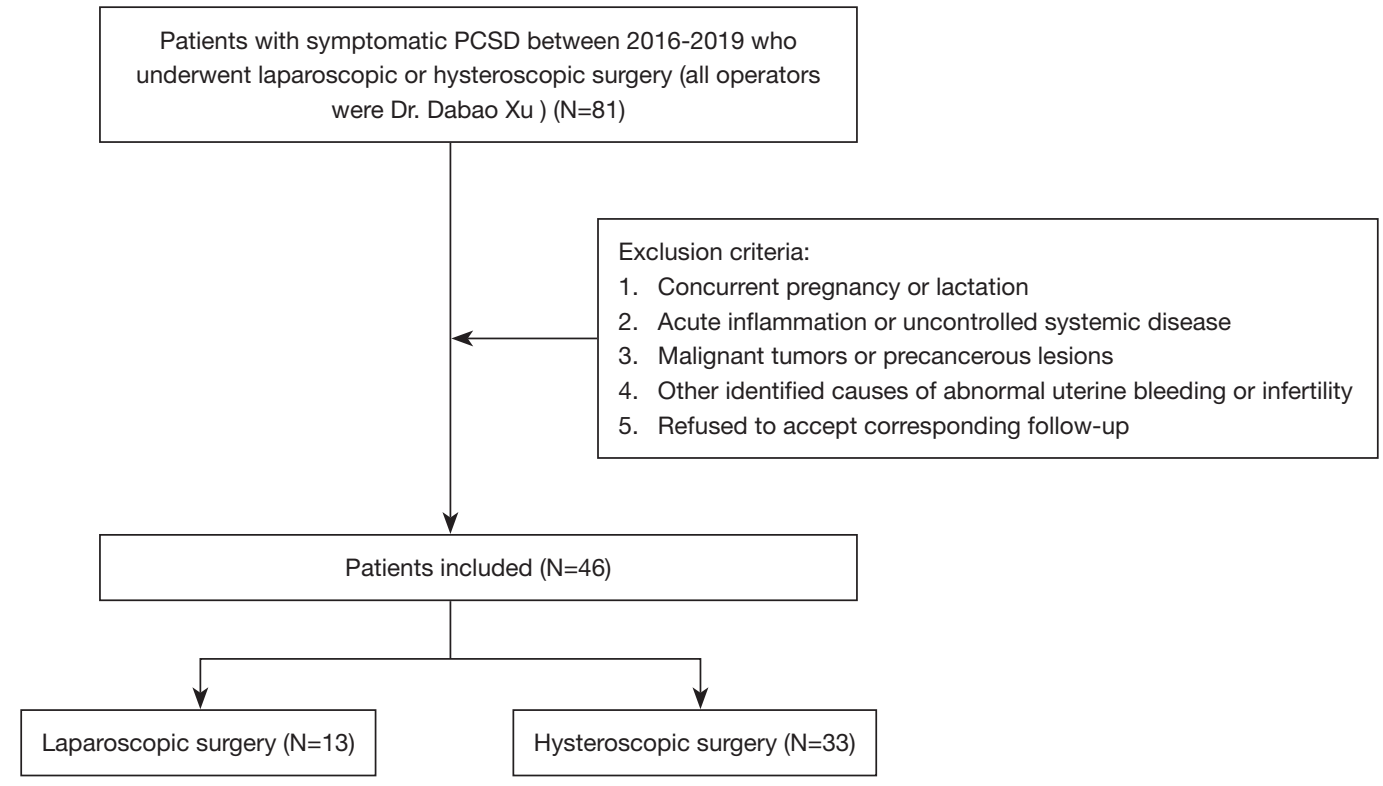

Figure 1 Flow chart of patient selection.

Hangzhou, Zhejiang, China), the peritoneal fold was incised from the bladder, which was pushed $2 \mathrm{~cm}$ away from the lower edge of the diverticulum. The surgeon identified the defect location and size by hysteroscopy, then completely opened the previous cesarean scar from one side to the other laparoscopically. The fibrotic tissue was excised from the defect. Bidirectional absorbable suture (Ethicon Inc., Somerville, NJ, USA) was used to perform full-thickness suture for wound closure. Hysteroscopy was performed to evaluate the repair of the defect after closure of the peritoneum.

\section{Hysteroscopic surgery}

Hysteroscopic surgery was mainly applied to patients with no requirement of fertility preservation and RM more than $3 \mathrm{~mm}$. Hysteroscopy was performed by the surgeon with a bipolar resectoscope (KARL STORZ SE\&Co., Tuttlingen, Germary). The inferior edge of the defect was removed until its wall was continuous to the cervical canal, then endometrium in the bottom of the diverticulum was electrocauterized $(13,14)$.

\section{Follow-up method}

All participants were followed up 3 months post-operation, and once per year thereafter. The data were collected from medical records and telephone interviews, including patients' age, clinical manifestations, physical examination, PCSD-related parameters of MRI (including RM, length, width, and depth), gravidity and parity, history of cesarean section deliveries, intraoperative blood loss, operation time, hospitalization stay and expenses, duration of postoperative menstruation, number and outcomes of pregnancy, and delivery information. The clinical efficacy of postoperative menstruation was assessed based on clinical cure, improvement, and ineffectiveness. Clinical cure was defined as no postmenstrual spotting after the surgery. Improvement was defined as shortened postmenstrual spotting. Ineffectiveness was defined as no obvious change of menstruation after the surgery.

\section{Statistical analysis}

Categorical data were presented as frequency and percentage in each group, and analyzed by the chi-square test. Normally distributed data with were expressed as mean \pm standard deviation (SD), and analyzed by Student's $t$-test. Non-normally distributed data were shown as median and range and analyzed by the Mann-Whitney $U$ test. Statistical analysis was performed with the software Statistical Analysis System 9.4 (SAS Institute, Cary, NC, USA). The cut-off 
Table 1 Characteristics of participants before surgery

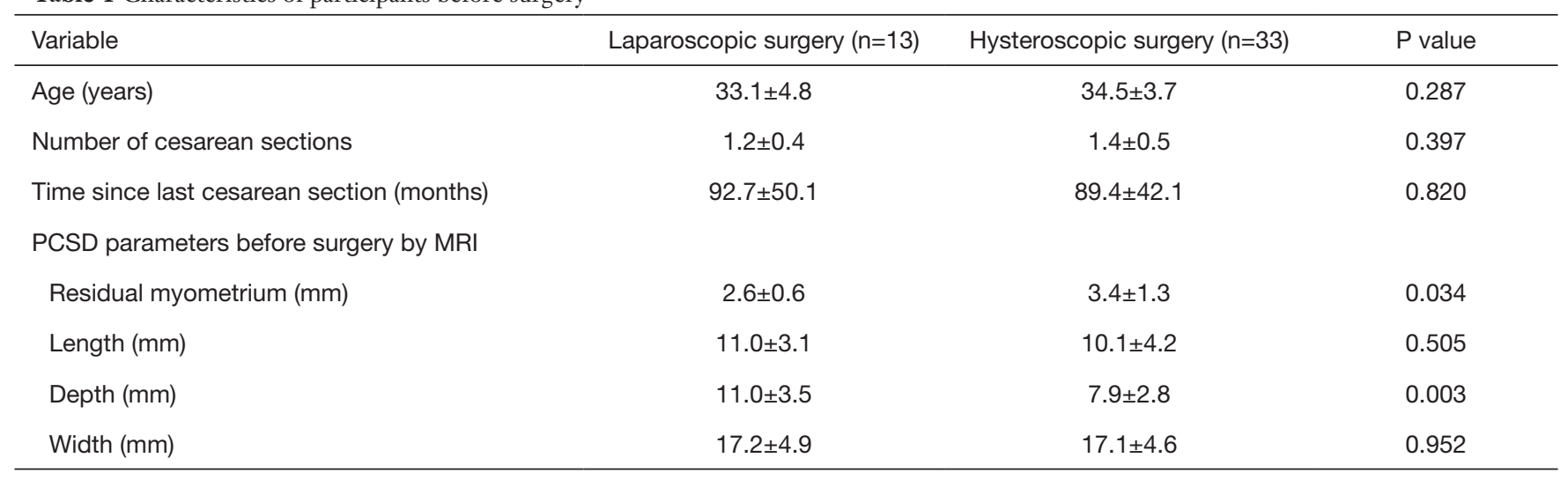

PCSD, previous cesarean scar defect; MRI, magnetic resonance imaging.

value for statistical significance was set at $\mathrm{P}<0.05$.

\section{Results}

\section{Population characteristics}

A total of 46 patients were included in this study. The followup duration was 1-4 years. Among them, 13 participants were treated with laparoscopic surgery, and 33 underwent hysteroscopic surgery. The characteristics of the 46 participants before the surgery are described in the Table 1 . There were no significant differences in the age, the numbers of cesarean section, or the time since last cesarean section between the 2 groups. The parameters of the defect assessed by MRI before the surgery are shown in Table 1. The defect was deeper in the laparoscopic surgery group than the hysteroscopic surgery group $(11.0 \pm 3.5$ vs. $7.9 \pm 2.8 \mathrm{~mm}$, $\mathrm{P}<0.05)$, and the $\mathrm{RM}$ was thicker in the hysteroscopic surgery group than the laparoscopic group $(3.4 \pm 1.3$ vs. $2.6 \pm 0.6 \mathrm{~mm}$, $\mathrm{P}<0.05)$. However, no significant differences were found between the 2 groups in other parameters, including the length and the width of the defect.

\section{Surgical outcomes and clinical efficacy of menstruation post-operation}

The surgical outcomes and clinical efficacy of postoperative menstruation are shown in Table 2. Significant differences were displayed in the operative times $(156.9 \pm 42.3 v s$. $40.7 \pm 38.9 \mathrm{~min}, \mathrm{P}<0.05)$, intra-operative blood loss (80.0 \pm 61.0 vs. $17.9 \pm 51.2 \mathrm{~mL}, \mathrm{P}<0.05)$, hospital stay $(7.1 \pm 1.6$ vs. $4.1 \pm 2.1$ days, $\mathrm{P}<0.05)$, postoperative hospital stay $(4.3 \pm 0.8$ vs. $1.5 \pm 1.1$ days, $\mathrm{P}<0.05)$, and hospitalization expenses
$(22,240.3 \pm 249.9$ vs. 9,547.1 $\pm 4,747.2$ yuan, $\mathrm{P}<0.05)$ between the laparoscopic surgery and hysteroscopic group. One patient had bladder injury, which was repaired immediately during laparoscopic surgery. There was no significant difference in the time of postoperative vaginal bleeding between the 2 groups. For the clinical efficacy, the cure rate was slightly higher in the laparoscopic surgery group, but this was not statistically significant [odds ratio (OR) 3.65, 95\% confidence interval (CI): 0.95 to $14.07, \mathrm{P}=0.082$ ]. No significant differences were shown in the incidence of improvement and ineffectiveness of postoperative menstruation between the laparoscopic and hysteroscopic surgery groups.

\section{Pregnancy outcomes}

A total of 4 participants in the laparoscopic surgery group and 11 in the hysteroscopic surgery group achieved subsequent pregnancies, the outcomes of whom are displayed in Table 3. The average time from surgery to pregnancy in the hysteroscopic surgery group was shorter $(11.75 \pm 4.5$ vs. $5.5 \pm 3.1$ months, $\mathrm{P}<0.05)$. In the laparoscopic surgery group, 3 out of 4 , and in the hysteroscopic surgery group, 6 out of the 11 participants became pregnant naturally, the rest underwent in vitro fertilization and embryo transfer (IVF-ET). One participant performed legally induced abortion later because of the personal issue, and the other participant was diagnosed of ectopic pregnancy after IVF-ET in the laparoscopic surgery group. Two participants underwent spontaneous abortion in the hysteroscopic surgery group. No significant differences were observed in the outcomes of pregnancy between the 
Table 2 Surgical outcomes and efficacy

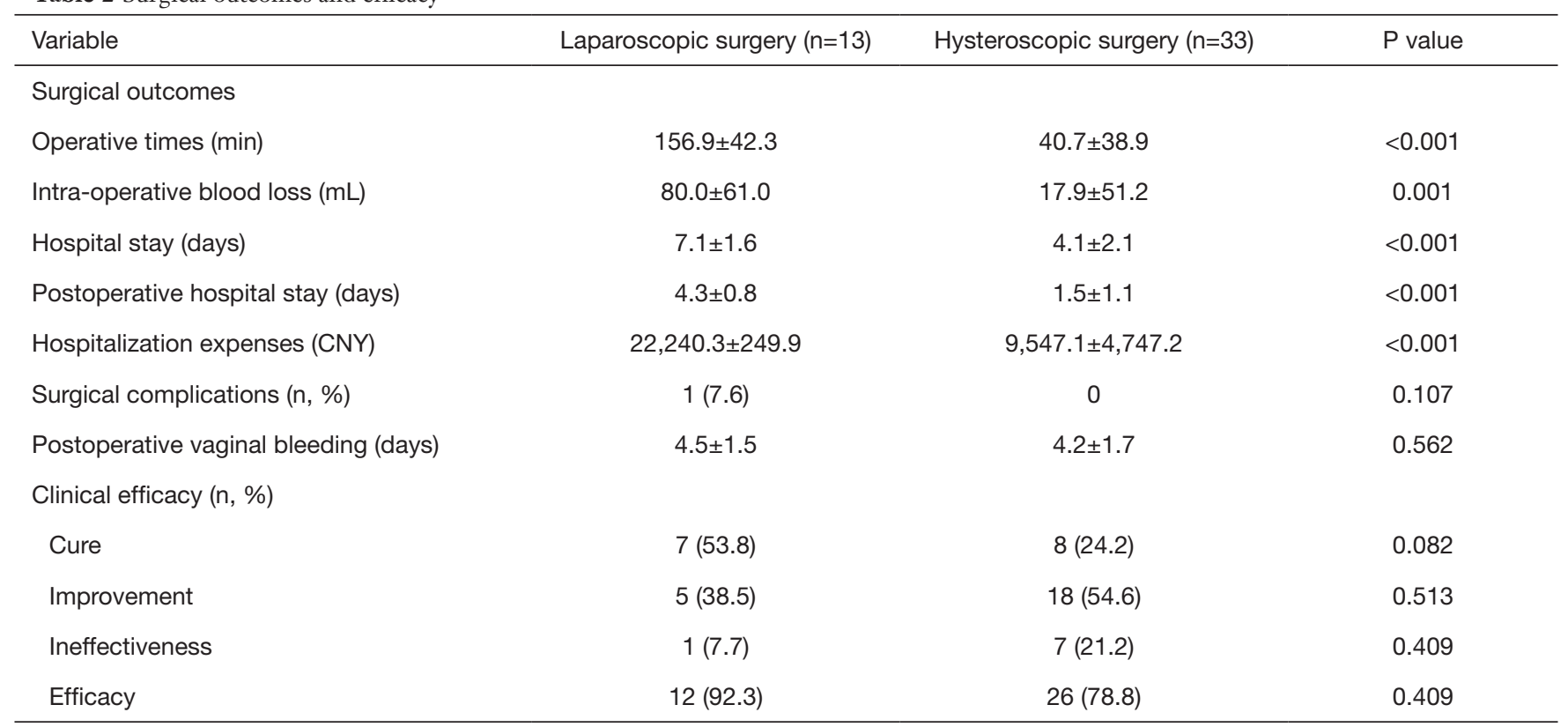

CNY, China Yuan.

Table 3 Pregnancy outcomes after surgery

\begin{tabular}{|c|c|c|c|}
\hline Variable & Laparoscopic surgery $(n=4)$ & Hysteroscopic surgery $(n=11)$ & $P$ value \\
\hline Average time to pregnancy (months) & $11.75 \pm 4.5$ & $5.5 \pm 3.1$ & 0.01 \\
\hline \multicolumn{4}{|l|}{ Conception approach (n, \%) } \\
\hline Natural & $3(75.0)$ & $6(54.5 \%)$ & 0.475 \\
\hline Assisted (IVF-ET) & $1(25.0)$ & $5(45.5 \%)$ & 0.475 \\
\hline \multicolumn{4}{|l|}{ Outcomes of pregnancy $(n, \%)$} \\
\hline Spontaneous abortion & 0 & $2(18.2 \%)$ & 0.521 \\
\hline Legally induced abortion & $1(25.0)$ & 0 & 0.389 \\
\hline Ectopic pregnancy & $1(25.0)$ & 0 & 0.389 \\
\hline Delivery & $2(50.0)$ & $9(81.8 \%)$ & 0.161 \\
\hline
\end{tabular}

IVF-ET, in vitro fertilization and embryo transfer.

two groups, including spontaneous abortion, legally induced abortion, ectopic pregnancy, and delivery.

\section{Delivery outcomes and complications during pregnancy and delivery}

Among the 15 pregnancies shown in Table 3, two participants in the laparoscopic surgery group and 9 participants in the hysteroscopic surgery group underwent the cesarean section deliveries to terminate pregnancy. The delivery outcomes and complications during pregnancy and delivery are shown in Table 4. One participant in the laparoscopic surgery group terminated the pregnancy at 32 gestational weeks because of intrahepatic cholestasis of pregnancy. One participant in the hysteroscopic surgery group terminated the pregnancy at 32 gestational weeks due to placenta previa and placenta increta. All two participants in the laparoscopic surgery group and two participants in the hysteroscopic surgery group were diagnosed with placenta previa. In addition, two participants in the 
Table 4 Delivery outcomes and complications after surgery

\begin{tabular}{|c|c|c|c|}
\hline Variable & Laparoscopic surgery $(n=2)$ & Hysteroscopic surgery $(n=9)$ & $P$ value \\
\hline Ended delivery $\geq 37$ weeks & 1 & 8 & 0.346 \\
\hline Premature delivery $<37$ weeks & 1 & 1 & 0.346 \\
\hline \multicolumn{4}{|l|}{ Pregnancy complications } \\
\hline Gestational diabetes mellitus & 0 & 2 & $>0.99$ \\
\hline \multicolumn{4}{|l|}{ Placenta } \\
\hline Placental abruption & 0 & 0 & \\
\hline Placenta increta & 0 & 1 & 0.182 \\
\hline
\end{tabular}

hysteroscopic group were diagnosed with gestational diabetes mellitus.

\section{Discussion}

As a long-term complication of CS, PCSD may present several symptoms, ranging from abnormal uterine bleeding, postmenstrual spotting or intermenstrual bleeding, menorrhagia, dysmenorrhea, chronic pelvic pain, to secondary infertility (5-8). So far, several surgical interventions have been applied to treat PCSD, including laparoscopic, hysteroscopic, and transvaginal surgery, and endometrial ablation (9). However, no surgery treatment is routinely recommended to asymptomatic PCSD patients. Hysteroscopy is a minimally invasive procedure, which has been shown to be effective for PCSD patients with abnormal uterine bleeding symptoms (15). Nevertheless, hysteroscopy is not suitable for those with fertility desire whose residual myometrium (RM) is $<3 \mathrm{~mm}$, because of the higher risk of bladder injury, uterine perforation, and uterine rupture $(16,17)$. Whereas, laparoscopy is characterized with a better visualization to treat the defect, strengthen the myometrial wall, minimize the risk of bladder injury, and clarify the cause of infertility and pelvic pain, which has been advocated for PCSD patients with large defect $(\mathrm{RM}<3 \mathrm{~mm})$ or fertility demand $(7,12,17,18)$. Both of these surgical interventions are widely applied to the PCSD patients in our hospital.

Abnormal uterine bleeding mainly presents postmenstrual spotting, is the principal symptom in PCSD patients $(6,9)$. Typical postmenstrual spotting is characterized by reduced vaginal bleeding after menses, which may persist for $2-12$ days $(9,19)$. Multiple hypotheses have been proposed to explain the etiology of abnormal uterine bleeding in patients with PCSD, among which the pouch in the lower uterine segment responsible for delaying the menstrual bleeding is the most important $(9,20)$. The drainage of blood from the uterus may be impaired by the pouch. Additionally, reduced contractility of uterine muscles around the cesarean scar, blood produced in situ, and blood with a higher mucus secretion in the niche are all additional recognized elements $(21,22)$. In our study, all participants presented postmenstrual spotting before the surgery. There was no statistical difference in the clinical efficacy post-operation between the 2 groups, despite the cure rate being higher in the laparoscopic surgery group. However, the patients in the hysteroscopic surgery group had less operative time, hospitalization time, and expenses than those in the laparoscopic group, and the intraoperative blood loss in the hysteroscopic surgery group was statistically less than that in the laparoscopic group. Meanwhile, the postoperative vaginal bleeding days in the 2 groups were similar. Therefore, hysteroscopic surgery is a more efficient treatment for PCSD patients.

Secondary infertility is another major symptom in patients with PCSD $(9,13,22)$. One of the potential mechanisms is the menstrual blood accumulated in the defect, which may have negative effect on cervix mucus quality, sperm transportation, and embryo implantation. The other is the chronic inflammatory condition of the uterus, especially nearby the cesarean scar $(13,22)$. Also, various obstetric complications, such as placenta previa, 
scar dehiscence, uterine rupture, and uterine cesarean scar pregnancy, are common in PCSD patients (23). Considering the strong fertility desire of these PCSD patients, some studies have shown promising reproductive outcomes $(24,25)$. Consistently, not including participants without the desire for preservation of fertility, the data in our study showed that 4 participants in the laparoscopic surgery group and 11 participants in the hysteroscopic surgery group achieved pregnancy after the surgery, and 2 of the 4 participants in the laparoscopic surgery group and 9 of the 11 participants in the hysteroscopic surgery group delivered successfully. A total of 4 participants were diagnosed with placenta previa in the two groups, and no uterine rupture was found in our study. These data suggest that laparoscopic and hysteroscopic surgery may benefit PCSD patients who wish to become pregnant. However, from the patient safety perspective, hysteroscopic surgery is more suitable for those with $\mathrm{RM}>3 \mathrm{~mm}$.

Prevention is better than cure. Although the most important factor to reduce the incidence of PCSD is to reduce the incidence of $\mathrm{CS}$, it is important to identify risk factors early in order to prevent the formation of a niche when CS is inevitable. Risk factors for the development of a PCSD include history of multiple CSs, longer duration and cervical dilatation of active labor before CS, lower uterine incision, extent of cervix dilatation at CS, surgical technique, postpartum infection, maternal body mass index, and gestational diabetes (26-30). Obesity and gestational diabetes could be affected by early management and interventions during pregnancy. CS in the late stages of labor must be carried out at an even higher level than we thought previously with appropriate consideration of the anatomical changes of the lower uterine segment (27). Longer operation time, more careful uterine closure and infection prevention are also needed to reduce the risk isthmocele development after CS.

In our study, one of the limitations was the small number of cases, and more stratifications could be classified according to the basic characteristics of patients. Thus, a prospective randomized trial is needed to further provide more information.

In conclusion, both laparoscopic and hysteroscopic surgery are safe and effective treatments for PCSD patients. Hysteroscopic surgery is more efficient for patients with PCSD.

\section{Acknowledgments}

Funding: This study was supported by Key Research and Development Program of Hunan Province (Grant No. 2022SK2033), Clinical Research Center of Hunan Province (Grant No. 2020SK4017) and National Key Research and Development Program of China (Grant No. 2018YFC1004800).

\section{Footnote}

Reporting Checklist: The authors have completed the STROBE reporting checklist. Available at https://dx.doi. org/10.21037/atm-21-4339

Data Sharing Statement: Available at https://dx.doi. org/10.21037/atm-21-4339

Conflicts of Interest: All authors have completed the ICMJE uniform disclosure form (available at https://dx.doi. org/10.21037/atm-21-4339). The authors have no conflicts of interest to declare.

Etbical Statement: The authors are accountable for all aspects of the work in ensuring that questions related to the accuracy or integrity of any part of the work are appropriately investigated and resolved. All procedures performed in this study involving human participants were in accordance with the Declaration of Helsinki (as revised in 2013). The study was approved by the Ethics Committee of Third Xiangya Hospital of Central South University (No: 2020-S625) and informed consent was taken from all the patients.

Open Access Statement: This is an Open Access article distributed in accordance with the Creative Commons Attribution-NonCommercial-NoDerivs 4.0 International License (CC BY-NC-ND 4.0), which permits the noncommercial replication and distribution of the article with the strict proviso that no changes or edits are made and the original work is properly cited (including links to both the formal publication through the relevant DOI and the license). See: https://creativecommons.org/licenses/by-nc-nd/4.0/.

\section{References}

1. Yu Y, Lin F, Dong W, et al. The effectiveness of financial intervention strategies for reducing caesarean section rates: a systematic review. BMC Public Health 2019;19:1080.

2. Liu X, Huang D, Landon MB, et al. Trends in Cesarean Delivery Rate after Cessation of the One-Child Policy in 
China. Am J Perinatol 2021;38:e84-91.

3. Li HT, Hellerstein S, Zhou YB, et al. Trends in Cesarean Delivery Rates in China, 2008-2018. JAMA 2020;323:89-91.

4. Li HT, Luo S, Trasande L, et al. Geographic Variations and Temporal Trends in Cesarean Delivery Rates in China, 2008-2014. JAMA 2017;317:69-76.

5. Allornuvor GF, Xue M, Zhu X, et al. The definition, aetiology, presentation, diagnosis and management of previous caesarean scar defects. J Obstet Gynaecol 2013;33:759-63.

6. Kremer TG, Ghiorzi IB, Dibi RP. Isthmocele: an overview of diagnosis and treatment. Rev Assoc Med Bras (1992) 2019;65:714-21.

7. Donnez O, Donnez J, Orellana R, et al. Gynecological and obstetrical outcomes after laparoscopic repair of a cesarean scar defect in a series of 38 women. Fertil Steril 2017;107:289-296.e2.

8. Bij de Vaate AJ, van der Voet LF, Naji O, et al. Prevalence, potential risk factors for development and symptoms related to the presence of uterine niches following Cesarean section: systematic review. Ultrasound Obstet Gynecol 2014;43:372-82.

9. Tower AM, Frishman GN. Cesarean scar defects: an underrecognized cause of abnormal uterine bleeding and other gynecologic complications. J Minim Invasive Gynecol 2013;20:562-72.

10. Fabres C, Aviles G, De La Jara C, et al. The cesarean delivery scar pouch: clinical implications and diagnostic correlation between transvaginal sonography and hysteroscopy. J Ultrasound Med 2003;22:695-700; quiz 701-2.

11. Yao M, Wang W, Zhou J, et al. Cesarean section scar diverticulum evaluation by saline contrast-enhanced magnetic resonance imaging: The relationship between variable parameters and longer menstrual bleeding. J Obstet Gynaecol Res 2017;43:696-704.

12. Li C, Tang S, Gao X, et al. Efficacy of Combined Laparoscopic and Hysteroscopic Repair of Post-Cesarean Section Uterine Diverticulum: A Retrospective Analysis. Biomed Res Int 2016;2016:1765624.

13. Gubbini G, Casadio P, Marra E. Resectoscopic correction of the "isthmocele" in women with postmenstrual abnormal uterine bleeding and secondary infertility. J Minim Invasive Gynecol 2008;15:172-5.

14. Raimondo G, Grifone G, Raimondo D, et al. Hysteroscopic treatment of symptomatic cesarean-induced isthmocele: a prospective study. J Minim Invasive Gynecol
2015;22:297-301.

15. Abacjew-Chmylko A, Wydra DG, Olszewska H. Hysteroscopy in the treatment of uterine cesarean section scar diverticulum: A systematic review. Adv Med Sci 2017;62:230-9.

16. Nezhat C, Falik R, Li A. Surgical management of niche, isthmocele, uteroperitoneal fistula, or cesarean scar defect: a critical rebirth in the medical literature. Fertil Steril 2017;107:69-71.

17. Marotta ML, Donnez J, Squifflet J, et al. Laparoscopic repair of post-cesarean section uterine scar defects diagnosed in nonpregnant women. J Minim Invasive Gynecol 2013;20:386-91.

18. Vervoort A, Vissers J, Hehenkamp W, et al. The effect of laparoscopic resection of large niches in the uterine caesarean scar on symptoms, ultrasound findings and quality of life: a prospective cohort study. BJOG 2018;125:317-25

19. Thurmond AS, Harvey WJ, Smith SA. Cesarean section scar as a cause of abnormal vaginal bleeding: diagnosis by sonohysterography. J Ultrasound Med 1999;18:13-6; quiz 17-8.

20. Borges LM, Scapinelli A, de Baptista Depes D, et al. Findings in patients with postmenstrual spotting with prior cesarean section. J Minim Invasive Gynecol 2010;17:361-4.

21. Bij de Vaate AJ, Brölmann HA, van der Voet LF, et al. Ultrasound evaluation of the Cesarean scar: relation between a niche and postmenstrual spotting. Ultrasound Obstet Gynecol 2011;37:93-9.

22. Florio P, Filippeschi M, Moncini I, et al. Hysteroscopic treatment of the cesarean-induced isthmocele in restoring infertility. Curr Opin Obstet Gynecol 2012;24:180-6.

23. Futyma K, Gałczyński K, Romanek K, et al. When and how should we treat cesarean scar defect - isthmocoele? Ginekol Pol 2016;87:664-8.

24. Gubbini G, Centini G, Nascetti D, et al. Surgical hysteroscopic treatment of cesarean-induced isthmocele in restoring fertility: prospective study. J Minim Invasive Gynecol 2011;18:234-7.

25. Fabres C, Arriagada P, Fernández C, et al. Surgical treatment and follow-up of women with intermenstrual bleeding due to cesarean section scar defect. J Minim Invasive Gynecol 2005;12:25-8.

26. Antila-Langsjo RM, Maenpaa JU, Huhtala HS, et al. Cesarean scar defect: a prospective study on risk factors. Am J Obstet Gynecol 2018;219:451-8.

27. Vikhareva O, Rickle GS, Lavesson T, et al. Hysterotomy 
level at Cesarean section and occurrence of large scar defects: a randomized single-blind trial. Ultrasound Obstet Gynecol 2019;53:438-42.

28. Park IY, Kim MR, Lee HN, et al. Risk factors for Korean women to develop an isthmocele after a cesarean section. BMC Pregnancy Childbirth 2018;18:162.

29. Stegwee SI, Jordans I, van der Voet LF, et al. Uterine caesarean closure techniques affect ultrasound findings and maternal outcomes: a systematic review and meta-analysis. Bjog 2018;125:1097-108.

30. Kamel R, Eissa T, Sharaf M, et al. Position and integrity of uterine scar are determined by degree of cervical dilatation at time of Cesarean section. Ultrasound Obstet Gynecol 2021;57:466-70.

(English Language Editor: J. Jones)

Cite this article as: Zhang Q, Lei L, Zhang A, Zou L, Xu D. Comparative effectiveness of laparoscopic versus hysteroscopic approach in patients with previous cesarean scar defect: a retrospective cohort study. Ann Transl Med 2021;9(20):1529. doi: $10.21037 /$ atm-21-4339 